\title{
Information Sharing, Community Development, and Deindividuation in the eLearning Domain
}

\author{
Nicole A. Cooke \\ University of Illinois at Urbana-Champaign
}

\begin{abstract}
In a study of the information behaviors of graduate students enrolled in an online Masters of Library and Information Science (MLIS) program, it was determined that learners engage in threaded discussions not only for cognitive purposes but for affective reasons as well. The information sharing among students was particularly prolific during a session in which medical ailments and information were discussed. Data were collected from an asynchronous class in a graduate LIS program, and were examined through learner/context analysis and textual analysis. This study used syllabi, course construction, specific assignments and requirements, and other details that contribute to the totality of the learning environment. Specific attention was given to the threaded discussions assigned in the class. This data provided insight into the students' activities and learning during 15 weeks, and enhanced the overall context for the small world that develops within an online learning community.

Students connected with their peers and instructor through copious exchanges of information during which a concerted and consistent effort was made to connect with one another by using personal names, engaging in humor and joke-telling, using emoticons, and expressing support and empathy.
\end{abstract}

\section{Introduction}

In a study of the information behaviors of graduate students enrolled in an online Masters of Library and Information Science (MLIS) program (Cooke, 2012), it was determined that learners engage in threaded discussions not only for cognitive purposes but for affective reasons as well. Students connected with their peers and instructor through copious exchanges of information (information sharing) during which a concerted and consistent effort was made to connect with one another by using personal names, engaging in humor and joke-telling, using emoticons, and expressing support and empathy. Referred to as connecting (Cooke, 2014), learners in these online environments initiated and maintained relationships, and developed community over the course of a semester by sharing information with one another. Connecting represents learners' attempts to interact with one another on a personal level by significant use of personal names, expressions of support, empathy, humor, and also evidence of instructor immediacy. 
This study addressed the following research questions: What patterns of information interactions are exhibited in the written interactions of the graduate students in an online learning community? What impact, if any, does the context of a small world community have on the information behaviors of online students? This research examined two courses, which are referred to as Technology and User Studies. User Studies is a theoretical class examining people's information seeking, searching, using, and valuing behaviors, and their impact on services provided by libraries and information organizations. Technology is a practical, hands-on class that introduces students to key concepts about the Internet, programming, and selected hardware and software that future library professionals may encounter, and examines their role in library services. In this graduate LIS program, classes are 15 weeks in length, and students typically take the two classes selected for this research concurrently in their first semester of study.

\section{Literature Review}

\section{Information Behavior}

Small worlds. The formation of community within the particular setting of online learning is attributed to the concepts of "small worlds," an information behavior theory posited by library and information science (LIS) scholar Elfreda Chatman (1991). Small worlds encompass several concepts including normative behavior; worldview; social types; information behaviors; and social network theory (Case, 2012; Yu, 2012; Huotari \& Chatman, 2001; Chatman, 2000; Chatman, 1999; Chatman, 1991). Huotari and Chatman described the theory in the following way:

In addressing the theory of small worlds, it is essential to remember that the reason the small world works is that it allows persons to share a similar cultural and intellectual space. That is, those things that hold this world together include a common assessment of information worthy of attention, social norms that allow its members to approach or ignore information and behaviors that are deemed by other inhabitants to be appropriate for this world. (Huotari \& Chatman, 2001, p. 352)

Students enrolled in online MLIS programs share the culture established by the overall library community, and they share an intellectual space and corresponding academic culture by engaging in a formal learning environment. Furthermore, by studying a specific subject area, in this case LIS, students seek and share specific information that assumes and promotes social norms, normative behaviors, and worldviews appropriate to the field of librarianship (Burnett \& Jaeger, 2011; Burnett et al., 2001; Chatman, 2000; Chatman, 1999). Online communities, especially those revolving around academic content, provide a common set of interests for their members.

\section{Affective Information Sharing}

Connecting is related to the affective or emotional realm of information behavior. Literature about the affective domain of information behavior is growing, and includes the feelings and mental states of users as they seek, use, and avoid information (Cibangu, 2015; González-Ibáñez, 2015; Savolainen, 2015a; Savolainen, 2015b; Fourie \& Julien, 2014; Nahl \& Bilal, 2007). Of particular note are the foundational works of the following information science scholars. Nahl's (2005, 2004, 2001) work addresses users' feelings of frustration, impatience, information overload, resistance to new information, and confusion. Mellon (2015, 1986) discusses feeling of anxiety, while Harris, Stickney, Grasley, Hutchinson, Greaves, and Boyd (2001) address disappointment in relation to information seeking. Kuhlthau (1993) investigates the feeling of uncertainty, often expressed as anxiety or worry, and Heinström (2014, 2004) also discusses stress, worry, and feelings of low confidence in information consumers. The findings of this research and their relation to this literature provides a natural link back to Chatman's (1992; 1996) work that address the small worlds of insiders and outsiders and retired women, and the emotions and feelings resulting from their information seeking and use. 


\section{Community Development}

Community was developed both inside and outside the formal course environment. This coalescence of connections enabled students to work with the course content collectively, and this group engagement made each class a community of practice (albeit one with a finite life cycle).

It is now generally accepted that people engaging in electronic exchanges are able to create communities - places with socially constituted norms, values, and expectations. Text serves as the lifeblood of these electronic places, conveying the ideas and feelings of participants that lead to the growth and evolution of a community or to its demise. ... A virtual community is comprised of members 'bound together for mutual service'. Members of virtual communities tend to provide advice and solutions to problems expressed by other members, even though they may be strangers to one another. (Burnett et al., 2003, paras. 1 \& 5)

As some students expressed, forging connections and creating community in an online environment can be difficult to accomplish due to the anonymity, asynchronicity, and lack of personal interaction and visual cues. Students said it was difficult to communicate solely by text, and expressed the desire to see their classmates. Forming relationships and a small world in this environment is different and perhaps more challenging than doing so in a face-to-face environment (Haythornthwaite \& Kendall, 2010; Kazmer, 2007, 2005; Haythornthwaite et al., 2000; Baym, 1997, 1995) and requires effort, risk-taking, and a willingness to trust (Finlay \& Willoughby, 2008). Interacting in the threaded discussions enabled the students to engage with course content while interacting with one another. The resulting conversations allowed students to “... publish, reflect, discuss, critique, and connect their knowledge” (Finlay \& Willoughby, 2008, p. 54).

\section{Distance Education}

The distance education literature (particularly within information science) addresses community development among online learners, especially as developed through computer-mediated communication (Trespalacious \& Rand, 2015; Poole 2013; Yukawa, 2010; Haythornthwaite \& Hagar, 2004; Haythornthwaite et al., 2000; Haythornthwaite, 2001; Kazmer, 2010, 2006, 2000). Since online learners do not have physical access to their instructors and fellow students, they must be purposeful in their interactions and efforts to make contact with one another. Socializing becomes a function facilitated by technology. Kazmer (2000) stated that forming community is an important coping skill for distance students.

They are in a new and unfamiliar learning environment, without physical classroom and with limited face-to-face contact. They face a variety of problems, social and technological, that students in more traditional programs do not. As students enter this new learning environment, they need support to help them gain entry to the community and to begin their interaction with others. (Kazmer, 2000, p. 2)

Haythornthwaite (2000) suggested that not only is community building important for distance learners, but community maintenance is vital as well. Technology facilitates community building, but students must make a concerted effort to maintain and nurture the initial bonds formed. Disengaging and not maintaining the social bonds and connections is referred to as "fading back" (p. 12). "Those who fail to make such connections feel isolated and more stressed than those who are more active in the community" (p. 2).

Palloff and Pratt (2001) state: "It is always important to remember that in the online environment, we present ourselves in text. Because it is a flat medium, we need to make an extra effort to humanize the environment” (p. 18). In the online classroom students interact exclusively via text, e-mails, journals, assignments, and threaded discussions. In this environment, it is important to promote social presence 
(Song \& Yuan, 2015; DeSchryver et al., 2009; Liu et al., 2009; Scollins-Mantha, 2008; Kehrwald, 2008; Ouzts, 2006; Biocca et al., 2003; Rettie, 2003; Richardson \& Swan, 2003; Stein \& Wanstreet, 2003; Tu, 2000; Tu \& McIsaac, 2002; Gunawardena \& Zittle, 1997). Social presence is defined as “... the degree of salience of the other person in the (mediated) interaction and the consequent salience of the interpersonal relationship. This is interpreted as the degree to which a person is perceived as 'real' in mediated communication” (Richardson \& Swan, 2003, p. 70). This realness can be thought of as “... the degree to which a user feels access to the intelligence, intentions, and sensory impressions" of the other members of the online environment (Tu, 2000, p. 28). Social presence needs to be cultivated, varies from group to group, depends on the particular technologies available to the learners, and the culture of the group in question (Gunawardena \& Zittle, 1997). Social presence is an important element in an online learning environment because of the lack of nonverbal and other interpersonal cues that are fundamental to face-to-face interactions in classrooms. Online cues and interactions are strategies learners use to overcome transactional distance, to get to know one another, and to form the basis for community in the online environment.

\section{Methods and Analysis}

\section{Approaches to the Research}

Informed by the constructs of phenomenography and virtual ethnography, this research employed textual analysis to examine the data collected from two online classes. The goals of this research were, in part, to: 1) Examine the dynamics of information behaviors in an asynchronous online classroom and, 2) identify factors that shape these behaviors. The study addressed the question: What information behavior patterns, if any, do students in an online asynchronous learning communities exhibit?

Two courses were selected and the respective instructors were asked for assistance with this study. Both instructors allowed the researcher access to their online course shells after the semester had ended. Each class contained 19 students. No incentives for participation were offered to the instructors or students. Data were collected from two online and asynchronous courses, Technology and User Studies, at an ALA accredited program in Library and Information Science at a university in the northeast United States. Data for this study consisted of the work product from these two classes (threaded discussions) and were collected over the course of one full academic semester (15 weeks) and examined through a textual analysis. The researcher did not participate in either class, but instead became immersed in the online course shells after the courses were completed.

This study was qualitative in nature, and was informed by phenomenography, virtual ethnography, and naturalistic inquiry. In order to answer the research question, it was necessary to become immersed in the small worlds of the LIS graduate students and investigate their experiences within the online learning environment. These approaches to qualitative research facilitated the discovery of students' information behaviors and the meanings associated with those behaviors. A phenomenographic approach is beneficial for uncovering and unpacking community members' experiences and analyzing the information exchanges and community development that occurred within the small world environment. Phenomenography was employed in this research as an interpretive method of identifying and unpacking the experiences of graduate students in the User Studies and Technology classes. The text-based discussions revealed learners' feelings of achievement, frustration, and community as they progressed through the semester.

Similar to traditional ethnography, virtual ethnography requires the researcher to be a member of and participant in the cyber culture (Rybas \& Gajjala, 2007; Teli et al., 2007) or online community being investigating (Hine, 2000, 2008; Paccagnella, 1997; Ward, 1999). Virtual ethnography lends itself to the 
immersive and extended study of online learning communities (Rutter \& Smith, 2005) and small worlds (Chatman, 1991).

This research used ethnographic/virtual ethnographic techniques. The main techniques are naturalistic inquiry and thick description of the participants' online learning environment, following the development of the participants' social interactions over time (Joinson, 2005) and identifying participants' patterns of information behavior through post-course immersion in the data. The researcher accordingly became immersed in the online course shells as an observer, not as a community participant, and observed the natural occurrences that transpired during a semester-long online course (Rutter \& Smith, 2005). The researcher also investigated “... the complex interaction between trust, intimacy, disclosure and time as complex relationships develop” (Carter, 2005, p. 149), and the influence of these relationships on the development of community and information exchange in the online classroom.

Phenomenography and virtual ethnography have qualities in common such as being immersive, highlighting members' meanings and community, and being context- specific. The combination of these two approaches enabled a specific lens through which to study the information behavior of learners in a small world. Phenomenography, an approach used in face-to-face study, unites with virtual ethnography to examine the specific needs and characteristics of an online learning environment. The two merge to create an atmosphere conducive to naturalistic inquiry and elucidated a set of principles that guided the researcher. The researcher specifically engaged in immersion and close observation of particapants and their lived experiences by examining the totality of the students' online activites as represented by threaded discussions.

In order to approach this research from a naturalistic perspective (Crystal \& Wildemuth, 2009; Erlandson, Harris, Skipper \& Allen, 1993; Lincoln \& Guba, 1986; Miles \& Huberman, 1994), and collect and analyze data that "... more closely reflect the real, lived experiences of the population of interest" (Crystal \& Wildemuth, 2009, p. 62), textual analysis was used for data analysis. This naturalistic approach is more context- specific than content analysis, and these methods enabled the researcher to elucidate new areas of human information behavior.

\section{Textual Analysis}

Threaded discussions are the most important and plentiful components of an online class as “... discussions can create a mutual sense of interaction and belonging that is essential to feeling the social presence of others” (Rovai, 2007, p. 103). Large volumes of content are produced in a short time, and because multiple students generate content, evaluating threaded discussions is challenging. "Evaluating online discussions is neither as simple nor as straightforward as one might suppose; it involves answering important questions about the instructor's purpose, the student learning to be measured, and the application of coding procedure” (Meyer, 2006, p. 83).

Discussion threads are the "media" through which the information behavior of online learners was ascertained (Fairclough, 2003, p. 30), and documents and forms of material culture examined (Lindlof \& Taylor, 2010). Lindlof and Taylor characterize material documents as "mute evidence" that cannot respond to researcher questioning, yet are rich sources of information that can be used to understand participants and phenomena of interest. Within material documents are critical incidents (Flanagan, 1954) that explicate the information behaviors and intents of participants.

Text, objects, and spaces do have a lot to 'say' when we read them alongside the living voices of informants and other social actors. Moreover, people do disclose their understandings of, and feelings about, the material world in other ways besides introspection - for example, by gesture, posture, facial expression, stories and accounts, jokes, ironic asides, confessions, even silence, (Lindlof \& Taylor, 2010, p. 271) 
Many forms of material culture are found in the threaded discussions, and to analyze this significant source of information, textual analysis (Krippendorff, 2004; McKee, 2003; Neuendorf, 2002; Spurgin \& Wildemuth, 2009) was employed. Similar to what was described by Lindlof and Taylor, McKee defined textual analysis as:

A way for researchers to gather information about how other human beings make sense of the world. It is a method ... for those researchers who want to understand the ways in which members of various cultures and subcultures make sense of how they are, and of how they fit into the world in which they live. (2003, p. 1)

Textual analysis is an interpretive approach that facilitated the discovery of information interactions, intents, flow, learning, connecting and the development of community, as they emerged in students' discussions. Texts, in the form of threaded discussions, provided insight into the learners' experiences and the meanings assigned to them. McKee emphasized the benefits of textual analysis by suggesting that "... the reason we analyze texts is to find out what were and what are the reasonable sense-making practices of cultures, rather than just repeating our own interpretation and calling it reality" (p. 19).

\section{Theory for Textual Analysis}

Textual analysis was conducted through the lens of the information behavior theory information intents (Todd, 2005). Information intents suggests that people seek and acquire knowledge to Get $a$ Complete Picture, to Get a Changed Picture, to Get a Clearer Picture, to Get a Verified Picture, and to Get a Position in the Picture (Todd, 2005, pp. 198-203). Newly acquired information adds to an individual's existing knowledge base and facilitates the expansion of viewpoint. Information intents allows information behavior patterns to be discovered.

To achieve consistency in the coding scheme, coding was conducted in three rounds, or exposures, occurring over a 60-day period. A total of 33 discussion threads were analyzed, 30 from the User Studies class, and three from the Technology class. (The Technology class only required three graded discussions.) All threads were analyzed with NVivo software, a tool for qualitative data analysis (http://www.qsrinternational.com). Codes used to analyze the threaded discussions were derived directly from the information intents theory (Todd, 2005) and from the results of a previous study that yielded a code named Getting Connected (Cooke, 2014). The codes were assigned to text in the threaded discussions and counted to determine the numbers of statements made over the course of the semester. Each thread was examined line-by-line, and codes were assigned to portions of the text in the discussions, ranging from a few words to a few sentences. A constant comparative approach was uses, always comparing new information with previously identified information, identifying patterns, refining coding assignments as needed, and developing new coding categories as needed (Glaser \& Strauss, 1967).

\section{Results}

The major component/source of data for this online class was the threaded discussions. Discussions were compulsory and comprised a portion of students' overall course grades. Students were given guidelines for participating in the discussions (one original post in each thread and two responses to classmates' postings, all of which should be substantive and draw from content contained in the lectures and course readings). Since students' writing styles vary, the length of entries varied. Some primarily used bullet points, while others wrote their posts as though the assignments were academic essays.

The threaded discussions were the bonding text, or "glue" in the classes and were the place of interactions between students and instructor. The students came together through discussions that 
incorporated course content, lectures provided by the professor, and scholarly articles about their topics of study. The weekly discussion thread questions were straightforward and asked students to compare and contrast the theories presented in their weekly readings, as well as discuss the implications of the theories for their role as library and information professionals.

A significant result of the research is the aforementioned element of connecting (Cooke, 2014). Many examples of connecting were evident in the threaded discussions of the two graduate classes. Written demonstrations of the online learners connecting with one another included:

- $\quad$ I agree, $X X X$.

- $\quad$ Like XXX, I think YYY has hit the nail on the head in her post.

- $\quad$ This is an excellent point, $X X X$.

- $\quad X X X$, you're so funny! :)

- $\quad$ Thank you, $X X X$, for the link to the article that defines the different terms related to "construct."

- $\quad X X X$, your library rocks!

- Wow, XXX - out of curiosity, how does this work logistically? Is somebody actually up all night answering queries? There's a budget for that?

Another dimension of Connecting was the affinity students felt for the instructor in the User Studies course, affinity that aided in the formation of community and facilitated understanding of course content. The instructor was a consistent source of comfort, encouragement, and humor, while providing more traditional functions such as giving feedback about performance, answering questions and providing correction as needed. The instructor maintained a strong presence throughout the semester in the threaded discussions.

\section{Health Information Sharing}

A specific and notable example of intense information sharing in the study involved the participants' discussion of health and medical information. Even though students were expressly told by the instructor not to disclose personal medical conditions or experiences in the threaded discussions, students shared an inordinate amount of personal information about themselves and family members, revealing a wide variety of personal conditions. Students revealed their ages and personal conditions including: stage four lung cancer, scleroderma, torn ACL ligaments, pregnancy and bed rest, pulmonary fibrosis, sinus conditions, spinal injuries, heart conditions, appendicitis, acute myelogenous leukemia, fibromyalgia, Lyme disease, drug abuse prevention measures, multiple sclerosis, osteochondritis, caring for elderly parents, and assorted gynecological issues.

Related discussion thread posts include:

- $\quad$ People who lived a life in the round were often seen to be information poor because their information came from a very small group of people. When thinking about it in that way, the fact that weak ties provide more and/or different information makes sense. People with whom we have weak ties live in a different circle and have a different knowledge base, like the nurses in Pettigrew's article. When we're sick we may be very tempted to only talk to our closest friends and family, but it may actually be more beneficial to branch out to others.

- $\quad$ Recently I was diagnosed with a very common problem that luckily does not include any scary outcomes. Even though my doctor reassured me that I needn't worry I couldn't really concentrate on what he was saying after he told me what was going on. So even though it was good to speak with him, and eventually I relaxed enough to hear what he 
was saying, it would have been nice if he could have directed me to some written information that I could take home with me, or even a trusted website that I could read at a later time. This way I could have gotten some more in-depth information at a time when I was better able to comprehend it.

- $\quad$ How can health care professionals use this knowledge to create similar atmospheres in their own practices? Perhaps waiting rooms could be turned into information grounds, not just by having pamphlets lying around that no one reads, but with nurses who are available to answer questions before and after a visit to see the doctor?

- $\quad$ Seven years ago, my back surgeon offered me a list of contacts who had previously undergone spinal fusion. The phone call provided a comfort and someone I could relate to. I felt like I was in a special club because no one in my circle of family/friends could share my experience. I have never recognized the value of this support group nor how my doctor valued his patients.

- $\quad$ So sometimes it's not just medical knowledge one needs, it's help navigating the system.

- We truly have to be our own patient advocates and cannot simply rely on information we get from the Internet.

In addition to having relevant topics to which participants can relate, common experiences proved to be a significant discussion generator. Everyone has had some type of experience with illness, and the need for quality and accessible medical information is universal. The relative anonymity of the asynchronous environment likely provided a layer of security and comfort that made students willing to share such personal information. Though students knew each other to some degree by the time this discussion occurred in the semester, their ignorance of each other's appearance combined with the fact that they did not have to see each other as they "spoke" probably made sharing personal medical details a non-threatening experience. In fact, this environment may have served to build an even stronger sense of community among this group and thereby permitted a deeper level of sharing.

Johnson and Case (2012) discuss the demographic characteristics of people who seek health information. Of particular interest is the characteristic of personal experience (pp. 51-56). The relevance or salience of the health information and the seeker's "proximity" (p. 55) to the information can influence the likelihood of sharing said found information with others. Information sharing can be a type of coping mechanism and a means of garnering social support (pp. 69-74), but health information is a common denominator with people, as everyone has a health issue in their immediate sphere and can relate to others in similar situations. This universality can hasten and amplify information sharing and community development.

These findings relate directly to this study's proposed research question that sought to determine the patterns exhibited in the written interactions of graduate students in an online learning community, and links this question to the idea that community formation influences the information behavior and sharing of students. Patterns of affective information exchange indicate the formation of community among students and suggest that the affective dimension of information sharing contributes to increased levels of information exchange and conversation in the discussions. Findings also indicated the interconnection of the cognitive and affective dimensions of the information intents schema. Information behavior and sharing are not compartmentalized into cognitive and affective dimensions, rather these dimensions complement one another to form a holistic and comprehensive view of information seeking, utilization, and sharing, and they illustrate how emotion is represented in text and contributes to the overall production of knowledge. 


\section{Discussion}

Findings from this study relate to the bodies of work treating the affective dimension of information behavior, distance education, and social psychology. Findings indicate that the phenomena of interest in this study also have roots in other areas of the literature, some outside the field of information behavior and library and information science. Drawing upon literature in psychology yields insight into the motivations that possibly undergird the type of information sharing that occurred around medical / health information. The medical / health information sharing that occurred in this study could be considered over-sharing, yet it seemed to facilitate some of the community development that occurred in the online learning environment. Specifically, the literatures on social sharing, help seeking, and disinhibition and deindividuation contribute to the understanding of these especially personal types of information sharing.

\section{Social Sharing}

Sharing is socially constructed, particularly when shared within digital and social networks, and can be fraught with politics, emotion, and other cultural elements - simply stated, sharing is "complicated" (Wittel, 2011, p.5). As an example of the complexities of sharing, John (2013) describes an aspect of information sharing that involves the sharing of personal details and feelings. In the class' threaded discussions, students primarily discussed academic texts and tasks, and their aspirations for their impending professional lives. The discussion threads focused on medical and health information behavior allowed them an opportunity to share personal details and feelings. Arguably, this was the first opportunity to be social with one another beyond a cursory level, particularly given the asynchronous nature of the class. In addition to revealing actual diagnoses, the discussion participants shared a substantial amount of information about their feelings about said diagnoses and ailments. For example, one student described being overwhelmed and not being able to relax to absorb the doctor's advice. Other students discussed welcoming and trusted medical professionals and environments. Student comments indicate that the contextual environment can be just as important as the information being received. These scenarios were common to the people in the class and established commonality that facilitated discussion and understanding.

In this way, information sharing is an act of communication distribution. Communication and information exchange are critical components of community building. John (year?) suggests that this kind of sharing is a result of people having "something in common" (p. 114) (in this case, medical conditions) and is a way of "imparting one's inner state to others" (p. 115). This social aspect of sharing, the sharing of feelings and emotion, can also be considered an important part of community building; affective sharing implies that a level of respect and trust exists within a group, and also serves to strengthen those bonds of trust and community.

\section{Help Seeking}

Help seeking appears in several bodies of literature, including information science, nursing, public health, and psychology (Abrahamson et al., 2008; Galdas, et al., 2005; Nicholas et al., 2004; Snowden, 1998; Ybarra \& Suman, 2006), and generally speaking, describes the phenomenon of an individual seeking medical / health information from the Internet or from a trusted source. Trusted sources can include both formal sources (medical professionals or counselors) or informal (peers or family), and the information being sought could be for the individual or for someone being cared for by that individual (known as Lay Information Mediary Behavior) (Abrahamson et al., 2008).

The literature suggests that help seeking is a secondary level of information solicitation and is used to confirm an existing diagnosis or self-diagnosis. Help seeking is also a means of seeking social support; social support eases pain and isolation for both those experiencing the ailment and for those 
caring for them. Ybarra and Suman (2006) suggest that this is the most important part of help seeking, more important than the validation aspect. They state "social support is a necessary component of somatic and mental health" (p. 38). The social support that results from help seeking can lessen stress and worry, can improve cognitive understanding of the medical issue at hand, can even lead to lifestyle changes (e.g., smoking cessation) (Abrahamson et al., 2008, p. 317), and can increase the resilience of both patients and caregivers (Nicholas et al., 2004, p. 17). One student in the study mentioned reaching out to a doctor and receiving a comforting phone call and additional information resources about their ailment, and indicated how valuable that kind of support was on a personal level.

Help seeking for social support could also provide an explanation for the high level of personal information sharing that occurred in the discussion threads. Learners shared personal medical / health information not only because it served as a point of commonality with their peers, but because it was an opportunity to validate their own diagnoses and situations and even gain new information about resources, cures, treatments, etc. Ultimately, this type of information sharing was perhaps solely an attempt to lean on a virtual shoulder of support and lessen their own stress and anxiety.

\section{Deindividuation}

The social psychology literature suggests that this type of over-sharing of information, a break from normative behavior, demonstrates a lack of inhibition called deindividuation (Suler, 2004; Coleman et. al, 1999; Zimbardo, 1970). This lack of inhibition or self-awareness in a specific setting can be attributed to the perception that individual group members are "not seen or paid attention to" (Festinger et al., 1952, p. 382), rather personal information was being disclosed to the group-at-large. Though students knew each other to some degree because of ongoing information sharing during the semester, their ignorance of each other's appearance combined with the fact that they did not have to see each other as they "spoke" likely made sharing personal medical details a non-threatening experience. In fact, this environment may have served to build an even stronger sense of community among this group and thereby permitted a deeper level of sharing. This sharing also enabled students to contextualize their own learning and facilitated the construction of new knowledge.

Patterns of help-seeking, deindividuation, social sharing, in conjunction with affective information behavior, indicate the formation of community among students, and suggest that this type of information sharing contributes to increased levels of interaction and conversation. Information behavior is not compartmentalized into cognitive and affective dimensions; rather, these dimensions complement one another to form a holistic and comprehensive view of information sharing and use, and illustrate how emotion contributes to the overall learning process.

\section{Conclusion}

The study looked at 38 online graduate students and this population yielded considerable data through the threaded discussion. Despite the rich results from the study there were several limitations. The study was limited by sample size, limited duration of data collection, concentration on one mode of online learning (asynchronous), and the examination of one LIS master's program. While interesting results about health information sharing emerged, that specific phenomenon was not the focus of the study; future research should focus on this phenomenon explicitly and should delve deeper into the possible theories behind medical / health information sharing. There is a wealth of literature about the health information seeking that happens on the Internet, but less of that literature focuses on information sharing and the motivations behind that sharing, especially in enclosed online environments (i.e., the online learning space). Future study should also examine face-to-face classrooms to see if comparable medical / health information sharing occurs in that setting. 
This research provided a basis for understanding how students in online LIS courses create connections and build community over the span of a semester. Specifically, an example of health information sharing within threaded discussions highlighted the small world development that can occur in an online learning environment. This examination, derived from Chatman's theory of small worlds (1991), included insights from studies in information science, education, psychology, and communication, and shed new light on online learners-their information behaviors and patterns of information sharing. Further, the instructional design of LIS distance education can benefit from these results and lead to more productive pedagogies in online classes. The insights gained from this research benefit not only the discipline of LIS, but also all others that utilize distance education technologies. Learning online is not just about delivering course content in an online format, but rather a way to put the learner first in the course design process by considering how they learn best and facilitating the development of learning communities.

Ultimately, small worlds do influence the information behavior of online students. Small worlds are forged through interaction and exchanges of information. These interactions increased the sense of community felt by students, and in turn this sense of community encouraged more interaction. In this way, small worlds are cyclical and dynamic entities. Small worlds are developed around context and depend upon interaction, norms, cognitive and affective information seeking and sharing, and can foster deep and sustained learning and construction of knowledge.

As indicated by the variety of opinions about information sharing, in multiple disciplines, sharing as it pertains to online learning and community development is a complicated phenomenon. This study begins to address the questions of what information sharing patterns students in online asynchronous learning communities exhibited and what role the formation of community played in the online learning environment. Learners in this online environment initiated and maintained relationships, and developed community over the course of a semester by purposely and freely sharing information with one another.

\section{References}

Abrahamson, J. A., Fisher, K. E., Turner, A. G., Durrance, J. C., \& Turner, T. C. (2008). Lay information mediary behavior uncovered: Exploring how nonprofessionals seek health information for themselves and others online. Journal of the Medical Library Association: JMLA, 96(4), 310-323. DOI: $\underline{10.3163 / 1536-5050.96 .4 .006}$

Baym, N. K. (1995). The emergence of community in computer-mediated communication. In Steve Jones (Ed.) CyberSociety: Computer-mediated communication and community (pp. 138-63). Thousand Oaks: Sage.

Baym, N. K. (1997). Interpreting soap operas and creating community: Inside an electronic fan culture. In Kiesler, S. (Ed.) Culture of the Internet (pp. 103-20). Mahwah, NJ: Lawrence Erlbaum.

Biocca, F., Harms, C., \& Burgoon, J. K. (2003). Criteria for a theory and measure of social presence. Presence: Teleoperators \& Virtual Environments, 12(5), 456-480. DOI: $\underline{10.1162 / 105474603322761270}$

Burnett, G., Dickey, M.H., Kazmer, M.M., \& Chudoba, K.M. (2003). Inscription and interpretation of text: A cultural hermeneutic examination of virtual community. Information Research, 9(4) paper 162. Retrieved from http://www.informationr.net/ir/9-1/paper162.html

Burnett, G., \& Jaeger, P. T. (2011). The theory of information worlds and information behaviour. New Directions in Information Behaviour, 1, 161. 
Carter, D. (2005). Living in virtual communities: An ethnography of human relationships in cyberspace. Information, Communication \& Society, 8(2), 148-167.

Case, D. O. (2012). Looking for information: A survey of research on information seeking, needs and behavior. Emerald Group Publishing.

Chatman, E. A. (2000). Framing social life in theory and research. New Review of Information Behaviour Research, 1, 3-17.

Chatman, E. A. (1999). A theory of life in the round. Journal of the American Society for Information Science, 50(3), 207-217.

Chatman, E.A. (1996). The impoverished life-world of outsiders. Journal of the American Society for Information Science, 47(3), 193-206.

Chatman, E.A. (1992). The information world of retired women. Westport, CT: Greenwood.

Chatman, E. A. (1991). Life in a small world: Applicability of gratification theory to information-seeking behavior. Journal of the American Society for Information Science, 42(6), 438-449. DOI: 10.1002/(SICI)1097-4571(199107)42:6<438::AID-ASI6>3.0.CO;2-B

Cibangu, S. K. (2015). A new direction in information science research: making information science a human science. Information Research, 20(3).

Coleman, L. H., Paternite, C. E., \& Sherman, R. C. (1999). A reexamination of deindividuation in synchronous computer-mediated communication. Computers in Human Behavior, 15(1), 51-65. DOI: $10.1016 /$ S0747-5632(98)00032-6

Cooke, N. A. (2014). Connecting: Adding an affective domain to the information intents theory. Library \& Information Science Research, 36(3), 185-191.

Cooke, N. A. (2012). The information use behaviors of graduate students in an online learning community (Doctoral dissertation, Rutgers University-Graduate School-New Brunswick).

Crystal, A. J. \& Wildemuth, B. M. (2009). Naturalistic inquiry. In B. M. Wildemuth (Ed.), Applications of social research methods to questions in information and library science (pp. 62-72). Westport, CT: Libraries Unlimited.

DeSchryver, M., Mishra, P., Koehleer, M., \& Francis, A. (2009, March). Moodle vs. Facebook: Does using Facebook for discussions in an online course enhance perceived social presence and student interaction? Society for Information Technology \& Teacher Education International, 1, 329-336.

Diener, E. (1977). Deindividuation: Causes and consequences. Social Behavior and Personality: An International Journal, 5(1), 143-155. DOI: http://dx.doi.org/10.2224/sbp.1977.5.1.143

Erlandson, D.A., Harris, E.L., Skipper, B.L., \& Allen, S.D. (1993). Doing naturalistic inquiry: A guide to methods. Newbury Park, CA: Sage.

Festinger, L., Pepitone, A., \& Newcomb, T. (1952). Some consequences of deindividuation in a group. Journal of Abnormal and Social Psychology, 47, 382-389. 
Fairclough, N. (2003). Analysing discourse: Textual analysis for social research. London, UK: Routledge.

Finlay, J. \& Willoughby, L. (2008). Exploring Online Learning Relationships: A Case Study in Higher Education. In S. Holland (Ed.), Remote relationships in a small world (pp. 53-73). New York: Peter Lang.

Fourie, I., \& Julien, H. (2014). IRS, information services and LIS research-a reminder about affect and the affective paradigm... and a question. Library Hi Tech, 32(1), 190-201.

Galdas, P. M., Cheater, F., \& Marshall, P. (2005). Men and health help- seeking behaviour: Literature review. Journal of advanced nursing, 49(6), 616-623. DOI: 10.1111/j.1365-2648.2004.03331.x

González-Ibáñez, R. (2015). Affective Dimension in Collaborative Information Seeking. In Collaborative Information Seeking (pp. 193-208). Springer International Publishing.

Gunawardena, C.N. et al. (1997). Analysis of a global online debate and the development of an interaction analysis model for examining social construction of knowledge in computer conferencing. Journal of Educational Computing Research, 17(4), 397-431.DOI: 10.2190/7MQV-X9UJ-C7Q3-NRAG

Harris, R., Stickney, J., Grasley C., Hutchinson, G., Greaves, L., \& Boyd, T. (2001). Searching for help and information: Abused women speak out. Library and Information Science Research, 23(2), 123-141. doi:10.1016/S0740-8188(01)00066-4

Haythornthwaite, C. (2001). Exploring multiplexity: Social network structures in a computer-supported distance learning class. The Information Society, 17(3), 211-226. DOI:10.1080/01972240152493065

Haythornthwaite, C. \& Hagar, C. (2005). The social worlds of the Web. Annual Review of Information Science and Technology, 39, 311-346. DOI: 10.1002/aris.1440390115

Haythornthwaite, C., Kazmer, M.M., Robins, J. \& Shoemaker, S. (2000). Community development among distance learners: Temporal and technological dimensions. Journal of Computer-Mediated Communication, 6(1). Retrieved from: http://jcmc.indiana.edu/vol6/issue1/haythornthwaite.html. DOI: 10.1111/j.1083-6101.2000.tb00114.x

Haythornthwaite, C., \& Kendall, L. (2010). Internet and community. American Behavioral Scientist, 53(8), 1083-1094.

Heinström, J. (2014). The emotional valence of information experience: relation to personality and approach to studying. In C. Bruce, K. Davis, H. Hughes, H. Cartridge, \& I. Stoodley (Eds.), Information Experience: Approaches to Theory and Practice (pp. 275-293). Emerald Group Publishing Limited.

Heinström, J. (2004). Fast surfers, broad scanners and deep divers: Fast surfing, broad scanning and deep diving. Journal of Documentation, 61(2), 228-247. DOI: http://dx.doi.org/10.1108/00220410510585205

Hine, C. (2000). Virtual Ethnography. London, Sage. 
Hine, C. (2008). Virtual ethnography: Modes, varieties, affordances. In N. Fielding, R. M. Lee and G. Blank (Eds.), The SAGE handbook of online research methods (pp. 257-268). Los Angeles, CA: Sage.

Huotari, M., \& Chatman, E. (2001). Using everyday life information seeking to explain organizational behavior. Library \& Information Science Research, 23(4), 351-366. doi:10.1016/S0740$\underline{\text { 8188(01)00093-7 }}$

John, N. A. (2013). The Social Logics of Sharing. The Communication Review, 16(3), 113-131. DOI: 10.1080/10714421.2013.807119

Johnson, J.D. \& Case, D.O. (2012). Health information seeking. New York: Peter Lang Publishing, Inc.

Joinson, A. N. (2005). Internet behavior and the design of virtual methods. Virtual methods: Issues in social reseach on the internet. In C. Hine (Ed.), New York, NY: Berg.

Kazmer, M. M. (2010). Disengaging from a distributed research project: Refining a model of group departures. Journal of the American Society for Information Science and Technology, 61(4), 758771.

Kazmer, M. M. (2007). How do student experiences differ in online LIS programs with and without a residency?. The Library Quarterly, 77(4), 359-383.

Kazmer, M. M. (2006, Summer). Creation and loss of sociotechnical capital among information professionals educated online. Library \& Information Science Research, 28(2), 172-191. $\underline{\text { doi:10.1016/j.lisr.2006.03.002 }}$

Kazmer, M. M. (2005). Community- Embedded Learning. The Library Quarterly, 75(2), 190-212.

Kazmer, M. M. (2000). Coping in a distance environment: Sitcoms, chocolate cake, and dinner with a friend. First Monday, 5(9). Electronic journal, no pagination. Retrieved from http://http://firstmonday.org/htbin/cgiwrap/bin/ojs/index.php/fm/article/view/791/700. ～DOI: http://dx.doi.org/10.5210/fm.v5i9.791

Kehrwald, B. (2008). Understanding social presence in text-based online learning environments. Distance Education, 29(1), 89-106. DOI: 10.1080/01587910802004860

Krippendorff, K. (2004). Content analysis: An introduction to its methodology. Thousand Oaks, CA: Sage Publications, Inc.

Kuhlthau, C. C. (1993). Seeking meaning: A Process Approach to Library and Information Services. Norwood, NJ: Ablex.

Lincoln, Y.S. \& Guba, E.G. (1986). But is it rigorous? Trustworthiness and authenticity in naturalistic evaluation. New Directions for Program Evaluation, 30, 73-84.

Lindlof, T. R. \& Taylor, B. C. (2010). Qualitative Communication Research Methods. Thousand Oaks, CA: Sage Publications, Inc.

Liu, S. Y., Gomez, J., \& Yen, C. J. (2009). Community college online course retention and final grade: Predictability of social presence. Journal of Interactive Online Learning, 8(2), 165-182. 
McKee, A. (2003). Textual Analysis: A Beginner’s Guide. London, UK: Sage.

Mellon, C. A. (2015). Library anxiety: A grounded theory and its development. College \& Research Libraries, 76(3), 276-282.

Meyer, K. A. (2006). The method (and madness) of evaluating online discussions. Journal of Asynchronous Learning Networks, 10(4), 83-97.

Miles, M. \& Huberman, M. A. (1994). Qualitative Data Analysis: An Expanded Sourcebook. $2^{\text {nd }}$ Ed. Thousand Oaks, CA: Sage.

Nahl, D., \& Bilal, D. (2007). Information and emotion: The emergent affective paradigm in information behavior research and theory. Information Today, Inc.

Nahl, D. (2005). Affective and cognitive information behavior: Interaction effects in Internet use. Proceedings of the American Society for Information Science and Technology, 42(1).

Nahl, D. (2004). Measuring the affective information environment of Web searchers. Proceedings of the $67^{\text {th }}$ Annual Meeting of the American Society of Information Science \& Technology, 41, 191-197. DOI: 10.1002/meet.1450410122

Nahl, D. (2001). A conceptual framework for explaining information behavior. Studies in Media and Information Literacy Education, 1(2), 1-16. DOI: 10.3138/sim.1.2.001

Neuendorf, K. A. (2002). The content analysis guidebook. Thousand Oaks, CA: Sage.

Nicholas, J., Oliver, K., Lee, K., \& O'Brien, M. (2004). Help-seeking behaviour and the Internet: An investigation among Australian adolescents. Advances in Mental Health, 3(1), 16-23. DOI: 10.5172/jamh.3.1.16

Ouzts, K. (2006). Sense of community in online courses. The Quarterly Review of Distance Education, 7(3), 285-296.

Palloff, R. M., and Pratt, K. (2001) Lessons from the Cyberspace Classroom: The Realities of Online Teaching. San Francisco, CA: Jossey-Bass.

Paccagnella, L. (1997). Getting the seats of your pants dirty: Strategies for ethnographic research on virtual communities. Journal of Computer-Mediated Communication, 3(1). Retrieved from http://jcmc.indiana.edu/vol3/issue1/paccagnella.html

Poole, N. (2013). Who do you know? A study of connectedness in online education and employment. Education for Information, 30(3, 4).

Rettie, R. (2003). Connectedness, awareness and social presence. PRESENCE 2003, 6th Annual International Workshop on Presence. Aalborg, Denmark. Retrieved from http://citeseerx.ist.psu.edu/viewdoc/download?doi=10.1.1.101.9820\&rep=rep1\&type=pdf

Richardson, J. C., \& Swan, K. (2003). Examining social presence in online courses in relation to students' perceived learning and satisfaction. Journal of Asynchronous Learning Networks, 7(1), 68-88.

Rovai, A. P. (2007). Facilitating online discussions effectively. Internet and Higher Education, 10(1), 7788. doi:10.1016/j.iheduc.2006.10.001 
Rutter, J. and G. W. H. Smith (2005). Ethnographic presence in a nebulous setting. In C. Hine (Ed.), Virtual methods: Issues in social reseach on the Internet (pp. 81-92). New York, NY: Berg.

Rybas, N. and R. Gajjala (2007). Developing cyberethnographic research methods for understanding digitally mediated identities. Forum: Qualitative Social Research 8(3): 1-15.

Savolainen, R. (2015a). Approaching the affective factors of information seeking: the viewpoint of the information search process model. Information Research, 20(1).

Savolainen, R. (2015b). Cognitive barriers to information seeking: A conceptual analysis. Journal of Information Science, 41(5), 613-623.

Scollins-Mantha, B. (2008). Cultivating social presence in the online learning classroom: A literature review with recommendations for practice. International Journal of Instructional Technology \& Distance Learning, 5(3), 1-15.

Snowden, L. R. (1998). Racial differences in informal help seeking for mental health problems. Journal of Community Psychology, 26(5), 429-438. DOI: 10.1002/(SICI)15206629(199809)26:5<429:AID-JCOP3>3.0.CO;2-M

Song, M., \& Yuan, R. (2015). Beyond Social Presence: Increasing Cognitive Presence through Meaningful Interaction. Global Learn, 1, 731-736).

Spurgin, K. M. \& Wildemuth, B. M. (2009). Content analysis. In B. M. Wildemuth (Ed.), Applications of social research methods to questions in information and library science (pp. 297-307). Westport, CT: Libraries Unlimited.

Stein, D., \& Wanstreet, C. (2003). Role of social presence, choice of online or face-to-face group format, and satisfaction with perceived knowledge gained in a distance learning environment. 2003 Midwest Research-to-Practice Conference in Adult, Continuing, and Community Education, 193198.

Suler, J. (2004). The online disinhibition effect. Cyberpsychology \& Behavior, 7(3), 321-326. doi:10.1089/1094931041291295

Teli, M., F. Pisanu, et al. (2007). The internet as a library-of-people: For a cyberethnography of onlne groups. Forum: Qualitative Social Research 8(3), 1-18.

Todd, R. J. (2005). Information intents. In K. E. Fisher, S. Erdelez \& L. McKechnie (Eds.), Theories of information behavior (pp. 198-203) (ASIST Monograph Series). Medford, N.J: Information Today.

Trespalacios, J., \& Rand, J. (2015). Using Asynchronous Activities to Promote Sense of Community and Learning in an Online Course. International Journal of Online Pedagogy and Course Design (IJOPCD), 5(4), 1-13.

Tu, C. H. (2000). On-line learning migration: From social learning theory to social presence theory in a CMC environment. Journal of Network and Computer Applications, 23(1), 27-37. doi:10.1006/jnca.1999.0099 
Tu, C. H. \& McIsaac, M. (2002). The relationship of social presence and interaction in online classes. American Journal of Distance Education, 16(3), 131-150. DOI: 10.1207/S15389286AJDE1603_2

Ward, K. (1999). Cyber-ethnography and the emergence of the virtually new community. Journal of Information Technology, 14(1), 95-105.

Wittel, A. (2011). Qualities of sharing and their transformations in the digital age. International Review of Information Ethics, 15(09), 4-8.

Ybarra, M. L., \& Suman, M. (2006). Help seeking behavior and the Internet: a national survey. International Journal of Medical Informatics, 75(1), 29-41. doi:10.1016/j.ijmedinf.2005.07.029

Yu, L. (2012). Towards a reconceptualization of the 'information worlds of individuals'. Journal of Librarianship and Information Science, 44(1), 3-18.

Yukawa, J. (2010). Communities of practice for blended learning: Toward an integrated model for LIS education. Journal of Education for Library and Information Science, 54-75.

Zimbardo, P.G. (1970). The human choice: Individuality, reason, and order versus deindividuation, impulse, and chaos. In W.J. Arnold \& D. Levine (Eds.), Nebraska Symposium on Motivation. University of Nebraska Press. Lincoln, Nebraska. 